\title{
Revisão de Literatura com Suporte de Revisão Sistemática Sobre a Intetegração de TDICs no Ensino da Matemática
}

\author{
Rodrigo R. M. de Lima ${ }^{1}$, Dennys L. Maia ${ }^{1}$ \\ ${ }^{1}$ Instituto Metrópole Digial (IMD) - Universidade Federal do Rio Grande do Norte \\ (UFRN) - CEP 59078-970 - Natal - RN - Brasil \\ rodrigorodriguesmlegmail.com, dennyseimd.ufrn.br
}

\begin{abstract}
The ICTs are alternatives to dynamize the Mathematics class, with this, the general objective of this work was to identify works that involved continuous collaborative formations of teachers that promote the integration of the ICTs in the teaching of mathematics. As a methodology, a research protocol was developed for academic works that were later cataloged in three axes. The results showed the researchers' concern to theorize about the benefits of new teaching methodologies in Mathematics. In addition, the teachers' training process was a prominent theme in most of the works. This allows a teaching practice more congruent with the reality of the students.
\end{abstract}

Resumo. As TDICs são alternativas para dinamizar a aula de Matemática, com isso, o objetivo geral deste trabalho foi identificar trabalhos que envolvessem formações continuadas colaborativas de professores que promovem a integração das TDICs no ensino da matemática. Como metodologia, elaborou-se um protocolo de pesquisa de trabalhos acadêmicos que posteriormente foram catalogados em três eixos. Os resultados mostraram a preocupação dos pesquisadores em teorizar sobre os beneficios de novas metodologias de ensino na Matemática. Além disso, o processo formativo dos professores foi tema em destaque na maioria dos trabalhos. Isso oportuniza uma prática docente mais congruente com a realidade dos alunos.

\section{Introdução}

Conhecer e acompanhar os avanços e os entraves no processo de aprendizagem discente sempre foi uma preocupação central na área da Educação. Diferente de décadas atrás, nas quais só era possível ter informações especializadas por meio da apropriação de livros ou em bibliotecas públicas, atualmente com o acesso à internet a forma de aquisição dessas informações ganhou novos e diversos caminhos e formatos. A autonomia e a independência se tornaram habilidades relevantes nesse contexto atual e a tendência é que sejam cada vez mais esperadas e exigidas nas próximas gerações.

A preocupação em destacar a importância da autonomia no aprendizado dos alunos está se refletindo na utilização de Tecnologias Digitais da Informação e Comunicação (TDICs), que têm se tornado ferramentas importantes na inovação da educação. Essas tecnologias possuem recursos que proporcionam habilidades para a troca de informações e prática de ações colaborativas e formas diversificadas da representação de um conteúdo disciplinar. 
VII Congresso Brasileiro de Informática na Educação (CBIE 2018)

Anais do XXIV Workshop de Informática na Escola (WIE 2018)

As TDICs possuem uma gama diversa de recursos que podem ser utilizados na prática pedagógica. Um desses recursos são os Objetos de Aprendizagem (OA) que se tratam de tecnologias granulares e diversificadas, que podem servir como suporte educacional no ensino da Matemática. Essa disciplina é essencial para a formação do aluno, pois é por meio dela que o aluno pode desenvolver a capacidade para a construção do pensamento reflexivo e do raciocínio lógico.

Já existem repositórios especificamente para essa disciplina, como é caso do projeto Objetos de Aprendizagem para Matemática (OBAMA) "que tem a proposta oferecer aos professores de Matemática da Educação Básica um ambiente que ofereça acesso, em único endereço web, ao maior número de OA para as aula" (BATISTA et al, 2017, p.300). A escolha do OA vai depender das reais necessidades do aluno e professor. O OBAMA tem a proposta de auxiliar professores da Educação Básica a encontrar recursos educativos digitais para diversificar as estratégias de ensino de Matemática em sala de aula, e também formar docentes para a busca, utilização e integração dos OA em processos de ensino e de aprendizagem (OBAMA, 2018).

Para se alcançar a integração da TDICs com os planos de aula dos professores, tudo começa com o Projeto Político Pedagógico (PPP) em que se faz um estudo da realidade, levando em conta os problemas, desafios do presente, quais as pretensões de transformação e a apresentação das linhas de ação no que se refere à gestão, currículo e qualificação. A segunda etapa é a proposta pedagógica que consiste no estudo contínuo das áreas do conhecimento. Se trata da reflexão coletiva sobre a prática docente. A terceira etapa é o Plano de trabalho docente que é a organização do trabalho do professor em sala de aula, com relação aos conteúdos e abordagens. Por último, o Plano de ação da escola que fica no nível de gestão, como a organização do trabalho escolar e criação das condições didático-pedagógicas.

Nesse sentido, é preciso incentivar formações para os professores que os tornem aptos a aplicar metodologias de ensino na matemática que busquem uma integração com as TDICs. E não apenas isso, a gestão escolar deve oportunizar esse novo pensamento de ensino desde o seu PPP até o seu plano de ação. Isso ainda não é uma realidade, problemas como a falta de incentivo por parte das secretarias, resistências dos professores em alterar sua forma de ensino se tornam obstáculos que dificultam a implantação dessa integração.

Diante dessa questão, tivemos como objetivo geral, identificar trabalhos que envolvam formações continuadas colaborativas de professores que promovam a integração das TDICs no ensino da matemática.

Essa pesquisa se justifica pela importância de se conhecer os estudos que estão sendo desenvolvidos a respeito das novas metodologias de ensino da Matemática, se os professores estão acompanhando as novas mudanças através da participação de formações das TDICs associadas à matemática e se realmente está ocorrendo a interação e colaboração entre professores de Matemática, informática e pedagogia, áreas basilares nessa discussão. 
VII Congresso Brasileiro de Informática na Educação (CBIE 2018)

Anais do XXIV Workshop de Informática na Escola (WIE 2018)

\title{
2. Referencial Teórico
}

Em um contexto em que a "atual sociedade é influenciada pela informatização e pelo paradigma tecnológico, caracterizado pela alta velocidade em que a informação é gerada, processada e compartilhada" (ROLANDO et al., 2015, p. 175) é imprescindível discutir sobre o desenvolvimento de aulas inovadoras, com diferentes tecnologias, já que os alunos estão inseridos em um contexto com amplo acesso à internet. Esse fenômeno oferece diferentes formas de comunicação e detém poder e potencial para influenciar a concepção de professores sobre o que seja ensinar e aprender.

Os alunos não se satisfazem mais com a forma de ensino do modelo tradicional, sem o uso de TDICs na sala de aula. A realidade dos alunos mudou e o modelo de educação precisa acompanhar essa mudança, envolvendo-os em atividades que traga um sentido para eles, ou seja, atividades que estejam associadas ao mundo que eles enxergam e a problemas que eles convivem. Cada criança leva consigo um propósito e um projeto pessoal que a escola deve mostrar os caminhos necessários para se alcançar a realização plena. Nesse sentido, as TDICs entram no cenário para auxiliar essa mudança de perspectiva:

\begin{abstract}
A tecnologia digital rompe com as formas narrativas circulares e repetidas da oralidade e com o encaminhamento contínuo e sequencial da escrita e se apresenta como um fenômeno descontínuo, fragmentado e, ao mesmo tempo, dinâmico, aberto e veloz. Deixa de lado a estrutura serial e hierárquica na articulação dos conhecimentos e se abre para o estabelecimento de novas relações entre conteúdos, espaços, tempos e pessoas diferentes (KENSKI, 2007, p.31).
\end{abstract}

Rolando et al (2015, p. 866) afirmam que as TDICs, no ensino "podem ser utilizadas para apoiar e favorecer a aprendizagem, criar situações baseadas em problemas do mundo real na sala de aula, como oportunidades de feedback e reflexão, na construção de comunidades de aprendizagem".

No campo do ensino de Matemática, disciplina já conhecida pela dificuldade dos alunos em aprendê-la, é muito importante considerar que as TDICs vêm se mostrando como forte aliada na busca da superação do baixo desempenho. Esse diagnóstico marca a vivência dessa disciplina por parte dos alunos, principalmente dos anos iniciais do Ensino Fundamental, onde a Educação Matemática é de suma importância. O desempenho nesse estágio, segundo dados do QEdu (2015), já se apresenta de forma deficitária e nos anos finais do Ensino Final, ocorre uma piora.

A referida disciplina faz parte da vida do ser humano e é através dela que se constrói a capacidade de raciocínio lógico e crítico. Esta capacidade é fundamental para se constituir um sujeito ativo e participante na sociedade; alguém que transforma sua própria realidade e busca propor melhorias para a sua sociedade. Ignorar a dificuldade dos alunos em construir em si mesmo o caráter dessa dimensão social que a Matemática traz é uma demonstração de descompromisso e incoerência com a função exercida pelo professor.

As TDICs vêm a ser alternativas interessantes para dinamizar a aula de Matemática e é no contexto de inovação pedagógica com suporte de tais tecnologias que surgem, por exemplo, os repositórios de Recursos Educativos Digitais (RED), que servem para reunir, organizar e compartilhar recursos didáticos disponíveis na internet, 
VII Congresso Brasileiro de Informática na Educação (CBIE 2018)

Anais do XXIV Workshop de Informática na Escola (WIE 2018)

como os Objetos de Aprendizagem (OA), que podem ser compreendidos como "qualquer recurso digital usado com objetivo educacional" (PINHEIRO; RUMENOS; TEZANI, 2016, p. 268).

Sobre os objetos de aprendizagem Wiley (2000, p.4) descreve qual a ideia base desta entidade digital:

\begin{abstract}
A ideia fundamental por trás dos objetos de aprendizagem é: os designers instrucionais podem construir componentes didáticos pequenos que podem ser reutilizados várias vezes em diferentes contextos. Além disso, os objetos de aprendizagem são geralmente entendidos como entidades digitais que podem ser entregues pela Internet, o que significa que qualquer número de pessoas pode acessá-las e usá-las simultaneamente.
\end{abstract}

Nesse sentido, os OAs atualmente são utilizados nas práticas pedagógicas de professores que buscam criar uma aula interativa e incentivar o trabalho colaborativo dos alunos. Sua utilização na Educação Matemática demonstra uma forma inovadora de oportunizar a construção do conhecimento do aluno, além disso, incentiva que esse processo de construção seja ativo, pois ele mesmo será levado a buscar sua própria forma de resolver os problemas da atividade proposta.

Percebe-se, portanto, uma necessidade de se aprofundar e modificar a formação colaborativa docente, principalmente quando se trata da integração de TDICs no plano de aula, visto que o momento de reflexão e construção da formação é determinante para o sucesso do engajamento dos professores com a proposta pedagógica como um todo pois, "no desenvolvimento das práticas docentes e dos outros partícipes escolares, engendram-se ações, desvelam-se vontades, opiniões, estratégias, organizações e (re)dimensionam-se atividades e propostas curriculares." (SOARES, 2016, p.110).

Se é preciso pensar no contexto do trabalho, as potencialidades dos alunos, e consequentemente, pensar em modelos de ensino que sejam mais congruentes com a realidade desses discentes, então é necessário refletir sobre metodologias que possam auxiliar nesse processo. Diante desse fato, considerando que as TDICs estão presentes no cotidiano do aluno, é desejável pensar em uma proposta da utilização dessas TDICs no plano de aula do professor.

O plano de aula do professor é considerado uma ferramenta importante, é nele que se define o que será ensinado, quais os métodos e procedimentos utilizados, como você vai avaliar o aprendizado do aluno, o cronograma de ensino e qualquer outra informação que possa ser guia na implementação do plano. O planejamento da integração das TDICs com os planos de aula dos professores pode ser feito por meio de uma pesquisa colaborativa que tem como ideia central a reflexão e construção conjunta do processo educativo. Dessa forma, o esforço conjunto leva ao alcance dos objetivos do ensino e consequentemente na aprendizagem do aluno. Nesse sentido, Ferreira e Ibiapina (2011, p. 122) conceitua esse contexto da seguinte forma:

o foco da Pesquisa Colaborativa é a vida real do professorado, bem como do processo educativo e as relações estabelecidas pelos professores e 
VII Congresso Brasileiro de Informática na Educação (CBIE 2018)

Anais do XXIV Workshop de Informática na Escola (WIE 2018)

pesquisadores como sujeitos da história que constroem no desenvolvimento da atividade docente, tornando-os mais conscientes do contexto no qual estão inseridos, alicerçados por visão e compreensão crítica das suas atuações. [...]

Com isso, entendendo a importância de um plano de aula colaborativo e incentivando a utilização de recursos digitais inovadores no momento de execução da aula, o professor de informática é o profissional mais adequado para dar suporte a esse momento.

\section{Metodologia}

Para compreender o estado da arte dos temas aqui abordados, elaborou-se um protocolo de pesquisa de trabalhos acadêmicos por meio de uma revisão sistemática, por meio dos periódicos que fazem parte do repositório da Coordenação de Aperfeiçoamento de Pessoal de Nível Superior (Capes). A pesquisa foi baseada na metodologia de Munzlinger, Narcizo e Queiroz (2012), na qual, por meio de uma série de protocolos de pesquisa, visa auxiliar o escopo da coleta dos trabalhos, facilitando, portanto, da busca até a extração dos dados.

\subsection{Questões de pesquisa}

A revisão sistemática sobre o tema de pesquisa teve como objetivo auxiliar na reflexão de questões pertinentes sobre assunto. Para isso, ela foi direcionada para atender às seguintes perguntas:

a) O que vem sendo discutido sobre a utilização de TDICs no ensino da Matemática?

b) Quais propostas de integração do plano de aula dos professores com as TDICs da Matemática nos anos iniciais do Ensino Fundamental têm sido realizadas?

c) Quais modelos de formação dos professores têm sido estudados para se tratar a integração das TDICs na sala de aula?

\subsection{Estratégia de busca}

A estratégia de busca escolhida para o procedimento foi através da busca automática por strings, sequência de caracteres que geralmente representam palavras, frases ou textos, utilizando conectivos condicionais mostradas na tabela abaixo. Para que gerasse um resultado satisfatório, e possível de se extrair os dados em tempo hábil e com qualidade, precisamos ir adicionando mais palavras chaves na string até alcançar um escopo satisfatório 32 artigos, com a última busca realizada em 01 de Maio de 2018.

A primeira string testada foi com a utilização dos termos: "educação matemática" AND "tecnologia educacional" AND "prática docente". A partir dela foi gerado um escopo muito grande, de 149 artigos, o que poderia acarretar em muitas fugas do tema do trabalho e o tempo para análise ser dispendioso, o que demonstrou que a nossa busca ainda não estava com um escopo bem delimitado e específico.

A segunda string testada, foi com a utilização dos termos "Educação Matemática" AND "Tecnologia Educacional" AND "Anos Iniciais" AND "Prática Docente" AND "Colaboração" com elas, foi possível chegar ao resultado desejado, em um melhor escopo, e dessa forma, ser elaborada uma melhor análise dos dados. 
VII Congresso Brasileiro de Informática na Educação (CBIE 2018)

Anais do XXIV Workshop de Informática na Escola (WIE 2018)

\subsection{Critérios de Inclusão e Exclusão}

Os critérios de inclusão e exclusão servem para delimitar o escopo desejado para a revisão da literatura, com isso, foram levados em consideração, os trabalhos que obedecessem as seguintes condições:

- Idioma: Português e Inglês;

- Data de publicação: Últimos 5 anos;

- Trabalhos que discutam, proponham ou apliquem formações continuadas e metodologias de ensino com integração de TDICs na Matemática no ensino;

- Artigos publicados em conferências, periódicos e revistas.

\subsection{Procedimentos de avaliação da qualidade dos estudos}

Durante uma revisão de literatura, é imprescindível que durante a leitura dos trabalhos, se observe e avalie a qualidade dos estudos. Por mais que a intenção não seja avaliar a qualidade de cada artigo, essa avaliação pode contribuir para o objetivo deste trabalho, principalmente para o desenvolvimento das discussões que serão elaboradas sobre os artigos lidos e principalmente qual é o foco de cada trabalho. Levaremos em consideração para essa avaliação fatores como:

- Elemento Primário: o estudo ilumina o significado subjetivo, as ações e o contexto do que está sendo pesquisado?

- Evidências de descrição adequada: são fornecidas descrições suficientemente detalhadas que permitam ao pesquisador interpretar o significado e contexto do que está sendo pesquisado?

- Evidência de amostragem teórica ou proposital: o estudo produz o tipo de conhecimento necessário para compreender a estrutura e o processo no qual está localizado?

- Relevância do Estudo: A relevância da pesquisa está claramente indicada?

\subsection{Estratégia de extração de dados}

A partir das leituras e avaliações, cada artigo selecionado foi catalogado nas seguintes categorias:

- Eixo 1: Trabalhos que envolvam a Educação Matemática, sejam eles revisões de literatura, relatos de experiência, estudo sobre o ensino da Matemática ou metodologias de ensino;

- Eixo 2: Trabalhos sobre discussão e/ou aplicação dos professores na integração das TDICs na Educação Matemática;

- Eixo 3: Trabalhos sobre discussão e/ou aplicação de formação docente para o ensino da Matemática.

No próximo capítulo, discutiremos os artigos estudados, e por fim, analisar os resultados obtidos. 
VII Congresso Brasileiro de Informática na Educação (CBIE 2018)

Anais do XXIV Workshop de Informática na Escola (WIE 2018)

\section{Resultados e Discussão}

Os artigos encontrados no eixo 1, aqueles relativos a revisões de literatura, estudo sobre o ensino da Matemática, metodologias de ensino, mostraram vertentes de pesquisa diversos como; exemplos de prática de metodologia ativa, como a Aprendizagem Baseada em Projetos (ABP) sobre conteúdos avançados da matemática conforme pesquisado por Souza e Fonseca (2017); considerações a respeito da ideia de educação baseada em competência relacionadas à Matemática conforme abordado por Bianchini et al (2017), interdisciplinaridade conforme estudado por Gonçalves e Pires (2014), investigação matemática no contexto da educação conforme investigado por Wicknoski (2017) e o uso de narrativas na pesquisa em Educação Matemática conforme visto em Nacarato, Passos e Silva (2014). O que esses artigos possuem em comum é a preocupação em teorizar sobre os benefícios de novas metodologias de ensino na Matemática. Porém, mesmo trabalhos que indicam metodologias ativas e inovadoras, não propõem a integração das TDICs. Isso abre portas para se pensar em metodologias ativas com uso de TDICs, criando assim, mais ideias para melhorar a prática pedagógica.

Foram encontrados no eixo 2 artigos sobre a aplicação das TDICs no ensino das Ciências da Natureza como também especificamente na Matemática. Ozelame (2016), por exemplo, desenvolveu uma pesquisa que buscou responder sobre como a tecnologia pode contribuir nas aulas de Ciências para a aprendizagem dos estudantes e se os recursos tecnológicos disponibilizados na escola são utilizados nas aulas de Ciências da Natureza. Os resultados da pesquisa indicaram que no discurso dos sujeitos, todos se mostraram favoráveis ao uso das tecnologias em sala de aula, porém os professores da escola investigada não fazem uso dos recursos tecnológicos disponibilizados na instituição. O motivo relatado está na falta de manutenção das máquinas, conforme conclusão dada por Ozelame (2016, p. 400). De fato, um dos agravantes, é a questão da infraestrutura, que é a base para implantação da integração. Porém, essa questão não é um fato isolado, aliado a isso, também existe a resistência ou até mesmo a falta de conhecimento do professor de modificar sua prática de ensino, como também o pouco incentivo de formações continuadas da própria secretaria de educação.

Outros trabalhos do mesmo eixo, como as pesquisas de Melo e Carvalho (2014), Javaroni e Zampieri (2015) e Bitante et al. (2016) de modo geral, discutem sobre a aplicação de TDICs em práticas docentes. Bitante et al. (2016) discute sobre a percepção dos professores sobre o impacto do uso da (TDIC) na aprendizagem dos alunos do Ensino Fundamental. Melo e Carvalho (2014) também nesse contexto, discute sobre o uso de software livre para o desenvolvimento da aprendizagem e colaboração. Javaroni e Zampieri (2015) buscou investigar as transformações no contexto da escola com o uso de tecnologias e fomentar o uso das TDICs nas práticas de professores de Matemática. Um ponto em comum entre todos foi a apresentação de seus artigos ou sob forma de revisão teórica ou sobre a experiência de uma aplicação de um projeto. Os resultados mostraram que houve um avanço na reflexão da construção do conhecimento entre os participantes e um amadurecimento do pensamento sobre os benefícios das TDICs na Educação Matemática.

Com relação ao eixo 3, relativos à formação docente no ensino da Matemática, percebemos que é uma linha de estudo que tem ganhado bastante atenção dos 
VII Congresso Brasileiro de Informática na Educação (CBIE 2018)

Anais do XXIV Workshop de Informática na Escola (WIE 2018)

pesquisadores. O artigo de Fiorentini e Oliveira (2013) Striquer (2014), Maia et al (2014), Paulin e Miskulin (2015), Merline, Santos e Magina (2017) e Zabel e Malheiros (2018) trazem essa discussão. Esses autores se preocuparam em discutir sobre práticas formativas que possam verdadeiramente contribuir para o futuro do professor que ensina Matemática conforme dito por Fiorentini e Oliveira (2013). Analisaram também se as propostas de formação continuada de professores de fato atingem a internalização de novos esquemas e modos de utilização de instrumentos por parte dos professores, Striquer (2014). Dentre os trabalhos citados, houve também a análise da forma como as interações mediadas pelas TDICs contribuíram para o desenvolvimento do professor de Matemática conforme destacado por Maia et al (2014), bem como a observação de uma mudança positiva na prática docente após o processo formativo conforme observado por Merlini, Santos e Magina (2017).

Outros trabalhos como os de Ponte et al (2016) e Santos e Merlini (2018) que demonstram os benefícios da colaboração entre os professores participantes da formação, em que essa interação contribui significativamente no resultado final do trabalho desenvolvido. As pesquisas abordaram práticas colaborativas, entre professores, com a integração das TDICs no ensino da Matemática. Foi encontrado o trabalho de Souza e Passos (2015) que teve como objetivo identificar a receptividade ao software SuperLogo por licenciandos em Pedagogia e por professores dos anos iniciais do Ensino Fundamental, participantes de um curso de extensão online, e investigou o modo como eles propuseram o uso do recurso tecnológico. Esse software, o Logo, é uma linguagem de programação que possibilita o processamento de listas e de criação de procedimentos, Souza e Passos (2015, p. 1028). Como resultado, os autores perceberam que eles formularam estratégias e construíram conceitos e ideias sobre a Matemática e o ensino; alcançaram o envolvimento ativo dos estudantes, e entenderam o software como mais um recurso que pode auxiliar na aprendizagem dos alunos. A posição dos autores sobre os resultados reflete, de modo geral, a visão dos professores que enxergam as contribuições que as TDICs trazem para o avanço do ensino e aprendizagem. Assim como o Logo, outros softwares educativos têm trazido novas formas de trabalhar conteúdos educativos para além do giz, quadro e aulas expositivas. Essas metodologias que utilizam a tecnologia provocam um envolvimento mais ativo dos alunos nas aulas. A atenção dada ao processo formativo é um ponto a ser destacado, são a partir delas que ocorre uma nova mentalidade que se refletem na forma de trabalho mais eficiente por parte dos docentes. A autoavaliação da prática deve ser sempre um ponto a ser revisado tendo em vista a necessidade de acompanhar como tem se dado o aprendizado em um contexto de tecnologias e de colaboração no ambiente escolar. Após a catalogação e avaliação dos trabalhos, gerou-se o gráfico abaixo:

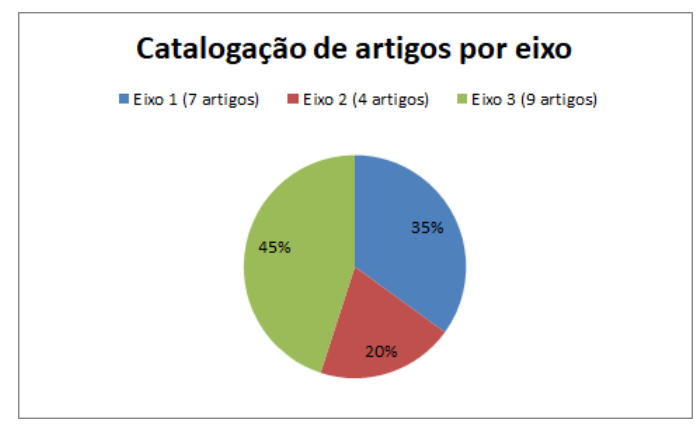

Gráfico 1: Catalogação dos trabalhos por eixo. 
VII Congresso Brasileiro de Informática na Educação (CBIE 2018)

Anais do XXIV Workshop de Informática na Escola (WIE 2018)

Foi possível perceber a diversidade de temas abordados sobre a Educação Matemática, seja teorizando ou refletindo sobre as práticas de ensino, desde revisões de literatura, metodologias de ensino às práticas educativas na Matemática com integração das TDICs.

Desta forma, fica clara a importância dada à integração das TDICs no processo de ensino e aprendizagem, corroborando com a mudança cultural em relação ao ensino nas escolas. Percebeu-se também, muitos trabalhos que tratavam sobre formação docente, ou seja, uma preocupação crescente sobre novas formas de ensino e a prática docente, inclusive através de formações continuadas colaborativas, onde os professores colaboravam nas ações realizadas no percurso da formação.

Apesar dos diversos trabalhos com TDICs, não foram encontrados na catalogação estudos ou práticas diretamente realizadas com a integração de OAs no ensino da Matemática, porém, muitas das aplicações dos trabalhos aqui descritos, possuem potencial para integrar OA no processo, como no trabalho sobre o Super Logo e no de uso de softwares livres, pode ser pensado em Objetos de Aprendizagem para essa integração no ensino da Matemática.

Essa ausência de pesquisas sobre OAs no Ensino da Matemática provocou uma inquietação, visto que se esperava encontrar o uso dessa ferramenta em diversas situações, seja no âmbito da formação docente ou em aplicações diretas com os alunos.

\section{Conclusão}

A revisão de literatura deste trabalho retornou resultados sobre os caminhos que a integração das TDICs na Educação Matemática vem tomando. A aplicação do protocolo da revisão sistemática deu segurança na coleta dos artigos, organizando e facilitando tanto a busca, como também a catalogação e análise dos trabalhos.

Isso oportunizou a reflexão do autor deste trabalho, principalmente para servir de informações pertinentes para o estudo e a aplicação da dissertação de mestrado a qual este artigo está vinculado.

Desse modo, foi possível perceber a oportunidade e a importância do pensar pedagógico na Matemática integrado as TDICs, inclusive com OA e diversos outros recursos disponíveis que auxiliem o processo de ensino e aprendizagem.

O ponto crucial desta revisão de literatura e que vêm sendo discutida por outros autores, foi refletir e compreender a viabilidade de se explorar a aplicação de práticas colaborativas entre professores e mensurar a contribuição que essa prática pode trazer para o ensino e aprendizagem. Essa ação pode beneficiar a prática docente e consequentemente, o aprendizado dos alunos, que precisam cada vez mais de um ensino mais congruente com a realidade que vivem.

Para trabalho futuro, fica a necessidade de ampliar a busca de estudos que vão além de artigos, incluindo trabalhos de teses e dissertações dos últimos cinco anos. Com isso, será possível obter maiores informações sobre a forma que as TDICs e especificamente, os OAs, estão sendo discutidos ou trabalhados nas pesquisas da pósgraduação. 
VII Congresso Brasileiro de Informática na Educação (CBIE 2018)

Anais do XXIV Workshop de Informática na Escola (WIE 2018)

\section{Referencial}

BATISTA, S. M.; CARVAlHO, R. A. D.; OliveIRA, A. M. D.; SILVA, A. C. N.; OLIVEIRA, N. I. D.; MAIA, D. L. OBAMA: um Repositório de Objetos de Aprendizagem para Matemática. VI Congresso Brasileiro de Informática na Educação (CBIE 2017). Anais dos Workshops do VI Congresso Brasileiro de Informática na Educação (WCBIE 2017).

FERREIRA, M. S.; IBIAPINA, I. M. L. de M. A pesquisa colaborativa como espaço formativo. In: MAGALHÃES, M. C. C.; FIDALGO, S. S. (Orgs). Questões de Métodos e de Linguagem na Formação Docente. Campinas, SP: Mercado de Letras, 2011, p. $119-140$.

KENSKI, V. M. Educação e tecnologias: o novo ritmo da informação. Campinas, SP: Papirus, 2007.

MUNZLINGER, E.; NARCIZO, F. B.; QUEIROZ, J. E. R. de. Sistematização de revisões sistemática em pesquisas da área de IHC. In: Proceedings of the 11th Brazilian Symposium on Human Factors in Computing Systems. Porto Alegre, RS, Brazil: Brazilian Computer Society, 2012. (IHC '12), p. 51-54. ISBN 978-85-7669262-1. Disponível em: http://dl.acm.org/citation.cfm?id=2400076.2400099.

OBAMA. Objetos de Aprendizagem em Matemática. Disponível em: https://www.imd.ufrn.br/portal/obama. Acessado em: 27 de junho de 2018.

PINHEIRO, Anderson Cangane; RUMENOS, Nijima Novello; TEZANI, Thaís C. Rodrigues. Repositórios de objetos de aprendizagem no ensino de ciências e matemática: uma breve análise. Infor, Inov. Form., Rev. NEaD-Unesp, São Paulo, v. 2, n. 1, p.266-288, 2016. ISSN 2525-3476

ROLANDO, L. G. R.; LUZ, M. R. M, P. da; SALVADOR, D. F. O conhecimento tecnológico pedagógico do conteúdo no contexto lusófono: uma revisão sistemática da literatura. Revista Brasileira de Informática na Educação (RBIE), v.23(3), p.5-37, 2015 .

SOARES, Maria Torres Neri. A proposta curricular em ação: caminhos formativos para o (re) pensar da organização pedagógica e a deficiência no espaço escolar. Research, Society and Development, v. 2, n. 2, p. 107-121, out. 2016

WILEY, D. A. Conecting learning objects to instructional theory: A definition, a methaphor anda a taxonomy. The Instructional Use of Learning Objets. Wiley,D.(Ed.) 2001. Disponível na URL: $<$ http://www.reusabilility.org/read/chapters/wiley.doc $>$. 2001. Acesso em $24 / 05 / 2017$ 